\title{
Quality analysis of anterior cervical discectomy and fusion in the outpatient versus inpatient setting: analysis of 7288 patients from the NSQIP database
}

\author{
Matthew J. McGirt, MD, ${ }^{1}$ Saniya S. Godil, MD, ${ }^{2}$ Anthony L. Asher, MD, ${ }^{1}$ Scott L. Parker, $M D,{ }^{2}$ and \\ Clinton J. Devin, MD³
}

${ }^{1}$ Carolina Neurosurgery \& Spine Associates, Charlotte, North Carolina; and Departments of ${ }^{2}$ Neurological Surgery and ${ }^{3}$ Orthopaedic Surgery, Vanderbilt University Medical Center, Nashville, Tennessee

\begin{abstract}
OBJECT In an era of escalating health care cost and universal pressure of improving efficiency and cost of care, ambulatory surgery centers (ASCs) have emerged as lower cost options for many surgical therapies. Anterior cervical discectomy and fusion (ACDF) is one of the most prevalent spine surgeries performed and is rapidly increasing with an expanding aging population. While ASCs offer cost advantages for ACDF, there is a scarcity of evidence that ASCs allow for equivalent quality and thus superior health care value. Therefore, the authors analyzed a nationwide, prospective quality improvement registry (National Surgical Quality Improvement Program [NSQIP]) to compare the quality of ACDF surgery performed in the outpatient ASC versus the inpatient hospital setting.

METHODS Patients undergoing ACDF (2005-2011) were identified from the NSQIP database based on the primary Current Procedural Terminology codes. Patients were divided into 2 cohorts (outpatient vs inpatient) based on the acute care setting documented in the NSQIP database. All 30-day surgical morbidity and mortality rates were compared between the 2 groups. Propensity score matching and multivariate logistic regression analysis were used to adjust for confounding factors and to identify the independent association of outpatient ACDF with perioperative outcomes and morbidity.
\end{abstract}

RESULTS A total of 7288 ACDF cases were identified (inpatient $=6120$, outpatient $=1168$ ). Unadjusted rates of major morbidity $(0.94 \%$ vs $4.5 \%, p<0.001)$ and return to the operating room $(O R)$ within 30 days $(0.3 \%$ vs $2.0 \%, p<0.001)$ were significantly lower in outpatient versus inpatient ACDF. After propensity matching 1442 cases (inpatient $=650$, outpatient $=792)$ based on baseline 32 covariates, rates of major morbidity $(1.4 \%$ vs $3.1 \%, p=0.03)$, and return to the $O R$ $(0.34 \%$ vs $1.4 \%, p=0.04)$ remained significantly lower after outpatient ACDF. Adjusted comparison using multivariate logistic regression demonstrated that ACDF performed in the outpatient setting had $58 \%$ lower odds of having a major morbidity and $80 \%$ lower odds of return to the OR within 30 days.

CONCLUSIONS An analysis of a nationwide, prospective quality improvement registry representing more than 250 hospitals demonstrates that 1 - to 2-level ACDF can be safely performed in the outpatient ambulatory surgery setting in patients who are appropriate candidates. In an effort to decrease cost of care, surgeons can safely consider performing ACDF in an ASC environment.

http://thejns.org/doi/abs/10.3171/2015.9.FOCUS15335

KEY WORDS ACDF; quality; inpatient; outpatient; NSQIP; anterior cervical discectomy and fusion

$\mathrm{S}$ INCE Smith, Robinson, and Cloward first described the procedure in $1958,4,15$ anterior cervical discectomy and fusion (ACDF) has become one of the most commonly performed spinal operations. ACDF is considered the gold standard for many degenerative cervical spine diseases due to its relative simplicity, minimal risk, and reliability. ${ }^{5}$ The total number of cervical spine procedures performed annually more than doubled from 1990 to 2000 , from 53,810 to $112,400 .{ }^{10}$ In fact, more ACDFs have been performed from 1999 to 2004 than were undertaken the entire previous decade. ${ }^{9}$ The number of ACDFs performed per year has risen steadily, with the rates of cer-

ABBREVIATIONS ACDF = anterior cervical discectomy and fusion; $A S A=$ American Society of Anesthesiologists; $A S C=$ ambulatory surgery center; COPD = chronic obstructive pulmonary disease; CPT = Current Procedural Terminology; GDP = gross domestic product; HTN = hypertension; NSQIP = National Surgical Quality Improvement Program; OR = operating room. 
vical fusion in the elderly rising 206\% from 1992 to 2005 among Medicare beneficiaries. ${ }^{18}$

The current growth in health care cost is unsustainable; the cost of health care has been estimated at nearly $18 \%$ of the US gross domestic product (GDP), and the cost of surgical care alone at $7 \%$ of the GDP. ${ }^{18}$ In this era of escalating health care cost and universal pressure of improving efficiency of care, focus has shifted to cost containment by reducing the number of hospital days, perioperative morbidity, and postsurgical hospital readmission. A growing cost-saving strategy is via outpatient surgeries and ambulatory surgery centers (ASCs), which tend to have facility fees that are $70 \%$ of those in the inpatient hospital setting. Technological advances and improvement in anesthesia and surgical techniques now allow numerous surgical procedures to be performed on an outpatient basis. Annual cost savings of up to $\$ 140$ million have been reported in the literature with the utilization of ASCs for spine surgery. ${ }^{13}$ Outpatient surgeries are not only a cost-effective option but also offer the theoretical benefit of reduction in nosocomial risks and medical errors associated with the inpatient hospital setting, as well as lead to more rapid recovery and higher patient satisfaction after surgery.

While there is growing evidence to support the safety and effectiveness of ASCs for lumbar decompression and discectomy, evidence on the safety and value of outpatient ACDF remains scarce. ${ }^{1-3,11,14,19}$ Surgical costs to the health care provider, the third-party payer, and the health care purchaser are less in the ASC setting, but these cost savings will only be realized across the care episode if the ASC setting provides equivalent (or superior) surgical quality. Therefore, the demonstration of equivalent surgical safety and quality is necessary to determine the relative value (quality/cost) of outpatient versus inpatient ACDF. We analyzed a nationwide, prospective quality improvement registry (National Surgical Quality Improvement Program [NSQIP]) to determine if there is a difference in surgical safety and quality for ACDF performed in the outpatient ASC versus inpatient hospital setting.

\section{Methods \\ Patient Population}

Patients undergoing ACDF from 2005 to 2011 were identified from the NSQIP database based on the primary Current Procedural Terminology (CPT) codes. NSQIP is a nationwide, prospective outcomes database to measure and improve quality of surgical care. Representative samples of patients are enrolled in the database from over 300 participating hospitals throughout all regions of the United States based on rolling cycles. Data integrity of the database is ensured via rigorous training, site audits, routine conference calls, and annual meeting of the participants. A total of 135 variables are collected in NSQIP database including preoperative risk factors, intraoperative surgical variables, and 30-day morbidity, mortality, and reoperation. Patients were divided into 2 cohorts (outpatient vs inpatient), and all perioperative outcomes and 30 -day morbidity were compared between the 2 groups. Major morbidity includes surgical site infection, deep vein thrombosis/pulmonary embolism, myocardial infarction, stroke, new neurological deficit, reintubation, postopera- tive hematoma, return to the operating room (OR), and systemic organ failure.

\section{Statistical Analysis}

All statistical analyses were performed using Stata (v.12.0, StataCorp). Parametric data were given as mean \pm standard deviation and compared via the Student t-test. Nonparametric data were given as median (interquartile range) and compared via Mann-Whitney U-test. Nominal data were compared via chi-square test. A $p$ value $<0.05$ was considered statistically significant.

Propensity score matching and multivariate logistic regression analysis were used to adjust for confounding factors and to identify predictors of perioperative outcomes and morbidity. For propensity matching, a nearest radius method was used to generate matched cohorts. Unmatched patients were excluded from any further analysis. The Student t-test and the chi-square test were used to compare comorbidities and complications between the matched cohorts.

In the multivariate logistic regression model, all significant independent variables as well as propensity score were included. Odds ratios of major morbidity and return to the OR for outpatient versus inpatient group were calculated.

\section{Results}

\section{Patient Population}

A total of 7288 ACDF cases from 2005 to 2011 were identified based on CPT codes from the NSQIP database (inpatient $=6120$, outpatient $=1168$ ). The mean patient age was $52.8 \pm 11.6$ years and $47.2 \%$ of the patients were male.

There were significant differences in the baseline characteristics of outpatient versus inpatient populations. The mean age was significantly higher in the inpatient group (53.5 vs 49.3 years, $p<0.001)$. There was a significantly higher proportion of males $(49.3 \%$ vs $46.1 \%, \mathrm{p}=0.04)$ and lower proportion of Caucasians $(86.9 \%$ vs $88.7 \%$, $p$ $=0.03$ ) in the inpatient group. The inpatient ACDF group had significantly higher comorbidities as compared with the outpatient group (diabetes, smoking status, functionally dependent, chronic obstructive pulmonary disease [COPD], hypertension [HTN], and American Society of Anesthesiologists [ASA] grade; $p<0.05$ ) (Table 1).

\section{Perioperative Quality}

The median number of levels for ACDF was similar in the inpatient and outpatient groups (1 vs 1$)$. Unadjusted rates of major morbidity $(0.94 \%$ vs $4.5 \%, \mathrm{p}<0.001)$ and return to the OR within 30 days $(0.3 \%$ vs $2.0 \%$, p < 0.001$)$ were significantly lower for outpatient versus inpatient ACDF (Table 2). None of the patients in the outpatient cohort were transferred to the inpatient setting immediately after surgery.

\section{Postmatched Analysis}

A total of 1442 cases (inpatient $=650$, outpatient $=792$ ) were propensity matched based on 32 covariates (Table 1). After propensity matching, there were no significant dif- 
TABLE 1. Comparison of demographic characteristics and comorbidities in outpatient versus inpatient ACDF cohorts from the NSQIP database*

\begin{tabular}{|c|c|c|c|c|c|c|}
\hline \multirow[b]{2}{*}{ Variable } & \multicolumn{2}{|c|}{ Unmatched } & \multicolumn{2}{|c|}{ Matched } & \multicolumn{2}{|c|}{ p Value } \\
\hline & $\begin{array}{l}\text { Outpatient } \\
(n=1168)\end{array}$ & $\begin{array}{l}\text { Inpatient } \\
(\mathrm{n}=6120)\end{array}$ & $\begin{array}{l}\text { Outpatient } \\
(\mathrm{n}=792)\end{array}$ & $\begin{array}{l}\text { Inpatient } \\
(\mathrm{n}=650)\end{array}$ & Unadjusted & $\begin{array}{c}\text { Propensity } \\
\text { Matched }\end{array}$ \\
\hline Mean age $\pm S D$, yrs & $49.3 \pm 10.1$ & $53.5 \pm 11.7$ & $49.2 \pm 10.1$ & $49.5 \pm 11.0$ & $<0.001$ & 0.61 \\
\hline Male & 46.1 & 49.3 & 45.1 & 43.7 & 0.04 & 0.60 \\
\hline Race† & 88.7 & 86.9 & 87.5 & 86.3 & 0.03 & 0.73 \\
\hline $\mathrm{DM}$ & 11.2 & 13.6 & 11.6 & 10.6 & 0.02 & 0.55 \\
\hline Smoker & 35.4 & 32.2 & 36.4 & 35.2 & 0.04 & 0.66 \\
\hline Dyspnea & 5.6 & 6.1 & 6.3 & 6.0 & 0.47 & 0.80 \\
\hline Dependent FS & 1.0 & 3.3 & 0.8 & 0.9 & $<0.001$ & 0.63 \\
\hline COPD & 2.5 & 3.7 & 2.0 & 3.1 & 0.04 & 0.20 \\
\hline HTN & 36.0 & 43.8 & 37.1 & 40.8 & $<0.001$ & 0.16 \\
\hline CAD & 3.6 & 4.3 & 4.5 & 3.7 & 0.26 & 0.42 \\
\hline CVA & 1.7 & 2.3 & 1.7 & 2.4 & 0.34 & 0.32 \\
\hline Mean BMI $\pm \mathrm{SD}, \mathrm{kg} / \mathrm{m}^{2}$ & $29.8 \pm 6.3$ & $29.7 \pm 6.5$ & $30.1 \pm 6.5$ & $29.6 \pm 6.5$ & 0.67 & 0.15 \\
\hline Steroid use & 2.8 & 2.9 & 3.0 & 2.8 & 0.90 & 0.77 \\
\hline Bleeding disorder & 0.77 & 1.4 & 1.0 & 0.8 & 0.10 & 0.63 \\
\hline Mean no. of levels \pm SD & $1.25 \pm 0.47$ & $1.29 \pm 0.54$ & $1.21 \pm 0.45$ & $1.23 \pm 0.49$ & 0.02 & 0.57 \\
\hline Wound classification $\ddagger$ & 0.50 & 1.0 & 0.50 & 0.61 & 0.11 & 0.78 \\
\hline ASA Grade & & & & & $<0.001$ & 0.34 \\
\hline 1 & 9.2 & 4.6 & 8.6 & 7.8 & & \\
\hline 2 & 62.3 & 56.4 & 62.4 & 59.4 & & \\
\hline 3 & 27.1 & 36.6 & 27.5 & 31.7 & & \\
\hline 4 & 1.3 & 2.4 & 1.5 & 1.1 & & \\
\hline
\end{tabular}

$\mathrm{BMI}=$ body mass index; $\mathrm{CAD}=$ coronary artery disease; $\mathrm{CVA}=$ cerebrovascular accident; $\mathrm{DM}=$ diabetes mellitus; FS = functional status.

* Values are percent of patients unless otherwise indicated. Bold type indicates statistical significance.

$\dagger$ White versus other races.

$\ddagger$ Dirty versus clean.

ferences in the patient demographics, comorbidities, and operative variables between the 2 groups. Rates of major morbidity $(1.4 \%$ vs $3.1 \%, \mathrm{p}=0.03)$ and return to the OR $(0.34 \%$ vs $1.4 \%, \mathrm{p}=0.04)$ remained lower in outpatient ACDF (Table 2).

\section{Multivariate Logistic Regression}

Adjusted comparison using multivariate logistic regression also demonstrated improved safety in the outpatient setting. After adjusting for all risk factors, patients in the outpatient ACDF cohort had 58\% lower odds of having a major morbidity $(\mathrm{p}=0.03)$ and $80 \%$ lower odds of return to the OR within 30 days $(\mathrm{p}=0.04)$ (Table 2).

\section{Discussion}

In an analysis of a nationwide, prospective surgical quality registry, the NSQIP database, we measured the differences in observed surgical quality and safety of outpatient versus inpatient ACDF surgery. In the current study, patients undergoing outpatient versus inpatient ACDF were propensity matched, and postmatch cohorts were similar with regards to all patient demographics and comorbidity profiles. Both propensity matched and multivariate logistic regression analysis demonstrated that 30-day morbidity and return to the OR were lower in the outpatient versus inpatient cohort. Patients in the outpatient ACDF cohort had $58 \%$ lower odds of having a major morbidity and $80 \%$

TABLE 2. Comparison of surgical safety and morbidity in outpatient and inpatient ACDF*

\begin{tabular}{|c|c|c|c|c|c|c|c|c|}
\hline \multirow[b]{2}{*}{ Variable } & \multicolumn{2}{|c|}{ Unmatched } & \multicolumn{2}{|c|}{ Matched } & \multicolumn{3}{|c|}{$p$ Value } & \multirow[b]{2}{*}{$\begin{array}{l}\text { Odds Ratio } \\
(95 \% \mathrm{Cl})\end{array}$} \\
\hline & $\begin{array}{l}\text { Outpatient } \\
(n=1168)\end{array}$ & $\begin{array}{l}\text { Inpatient } \\
(\mathrm{n}=6120)\end{array}$ & $\begin{array}{l}\text { Outpatient } \\
(n=792)\end{array}$ & $\begin{array}{l}\text { Inpatient } \\
(n=650)\end{array}$ & Unadjusted & $\begin{array}{c}\text { Propensity } \\
\text { Matched }\end{array}$ & Multivariate & \\
\hline Major morbidity & 0.9 & 4.5 & 1.4 & 3.1 & $<0.001$ & 0.03 & 0.03 & $0.42(0.19-0.92)$ \\
\hline Return to OR & 0.3 & 2.0 & 0.34 & 1.4 & $<0.001$ & 0.04 & 0.04 & $0.20(0.04-0.94)$ \\
\hline
\end{tabular}

* Values are percent of patients unless otherwise indicated. Bold type indicates statistical significance. Outpatient ACDF was associated with significantly lower surgical morbidity and return to $\mathrm{OR}$ within 30 days as compared to inpatient ACDF. 
lower odds of return to the OR within 30 days. Thus, our results suggest that ACDF can be performed with similar or potentially greater safety and quality in the outpatient versus inpatient setting.

Due to advancements in surgical techniques and anesthesia care, various surgical procedures that were previously considered safe only in the inpatient setting are now being performed in the outpatient setting. The push for hospitals and surgeons to promote ASCs pertains not only to safety and increased efficiency but also to significant cost savings associated with outpatient surgeries. The literature reports cost savings of up to $\$ 140$ million associated with the utilization of ASCs for spine surgery. ${ }^{13}$

The safety and effectiveness of outpatient lumbar spine surgery has been reported in numerous studies dating back as far as early 1990s. ${ }^{1-3,11,14,19}$ However, the reports on safety of ACDF as an outpatient procedure are scarce. One of the major contributing factors to reluctance to perform ACDF in the outpatient setting is the potential complication of airway compromise due to airway swelling or postoperative hematoma. However, this complication is almost always recognizable within the first 4 hours after surgery, well within the time frame of perioperative observation in the ambulatory surgery setting. A few reports to date on outpatient ACDF surgery demonstrate the safety of ACDF in the ASC setting, with surgical morbidity ranging from $0.3 \%-5.2 \% .6,7,12,16,17$ Lied et al. and Garringer and Sasso concluded that ACDF can be safely performed in the outpatient setting with a sufficient postoperative observation period of up to 4 hours. ${ }^{6,7}$ A study by Silvers et al. comparing outpatient versus inpatient $\mathrm{ACDF}$ in 103 consecutive patients demonstrated equal complication rates $(2 \%)$ in both the groups. ${ }^{13}$ Similarly, a study by Liu et al. involving 109 patients did not demonstrate any significant differences in outcomes between outpatient and inpatient ACDF cohorts. ${ }^{8}$ Our study also demonstrates safety of outpatient ACDF, with those who underwent outpatient ACDF having 58\% lower odds of having a major morbidity and $80 \%$ lower odds of return to the OR within 30 days. Additionally, Lied et al. and Sheperd and Young report patient satisfaction after outpatient ACDF as high as $91 \%-100 \%$ ?.12 The importance of our findings across the NSQIP network of hospitals is that these initial single-center reports of outpatient ACDF safety were reproduced throughout US health care centers in this national perspective. With diminishing health care dollars and evolving health care reform, increase in health care cost is simply not sustainable. While the acute care episode is the largest contributor to spine surgical cost, the greatest variability in cost occurs with the wide range in incidence of complication, hospital readmission, and reoperation during the postacute care episode. Our results suggest that in addition to lower facility fees, as previously reported, ASCs may also predispose to a reduction in adverse health care events, further reducing cost across the episode of care. Due to the short length of surgery, mild to moderate postoperative pain, and quick recovery, $\mathrm{ACDF}$ is well suited for an outpatient setting. As accountable care organizations, clinically integrated networks, and population-based capitated payment models emerge, outpatient $\mathrm{ACDF}$ may provide the cost containment needed to care for these patient populations, while also improving quality. Moreover, patient and provider incentives to encourage outpatient ACDF may provide significant benefit to thirdparty payers and health care purchasers in current feefor-service models. An economic analysis by Silvers et al. involving patients undergoing outpatient ACDF suggested an average cost savings of $\$ 1800$ per patient, leading to a potential cost savings of up to $\$ 140$ million in 1996 if all 1- to 2-level ACDFs were performed in the outpatient setting. ${ }^{13}$ Adjusting for utilization of ACDF in 2012, annual cost savings may be as high as $\$ 400$ million annually.

The findings of this study should be interpreted in light of the inherent limitations and weaknesses. Although, most of the prior studies, as well as our current nationwide review, highlight the safety and lower odds of major morbidity of outpatient ACDF, it is important to remember that selection bias in these studies cannot be completely eliminated. Patients undergoing outpatient versus inpatient ACDF were propensity matched and were similar with regard to all surgical risk factors, but there can still be bias associated with nonrandomization as well as surgeon experience and efficiency/experience of outpatient centers and hospital staff. The level of surgeon expertise, experience of house staff, and competence of outpatient centers/ hospitals have not been accounted for in the analysis. Data were used from the NSQIP database, and ACDF cases were identified based on CPT codes. There is no way to differentiate whether the patients had cervical radiculopathy or myelopathy, and outcomes can differ in these 2 patient populations. The wide scope that NSQIP provides in surgical quality analysis supports previous single-center reports that ACDF can be safely performed in the lowercost ASC setting; however, inpatient surgery will always be more appropriate for some patients, and surgeon judgment is necessary in these cases. Furthermore, most of the cases included in the analysis were 1- to 2-level ACDFs, and further studies and evidence are necessary to determine if the outpatient setting is appropriate for multilevel ACDF cases.

\section{Conclusions}

An analysis of a nationwide, prospective quality improvement registry representing more than 250 hospitals demonstrates that 1- to 2-level ACDFs can be safely performed in the outpatient ambulatory surgery setting in patients who are appropriate candidates. In an effort to decrease cost of care, surgeons can safely consider performing $\mathrm{ACDF}$ in an ASC environment.

\section{References}

1. Best NM, Sasso RC: Success and safety in outpatient microlumbar discectomy. J Spinal Disord Tech 19:334-337, 2006

2. Bookwalter JW III, Busch MD, Nicely D: Ambulatory surgery is safe and effective in radicular disc disease. Spine (Phila Pa 1976) 19:526-530, 1994

3. Cares HL, Steinberg RS, Robertson ET, Caldini P: Ambulatory microsurgery for ruptured lumbar discs: report of ten cases. Neurosurgery 22:523-526, 1988

4. Cloward RB: The anterior approach for removal of ruptured cervical disks. J Neurosurg 15:602-617, 1958

5. Fowler SB, Anthony-Phillips P, Mehta D, Liebman K: 
Health-related quality of life in patients undergoing anterior cervical discectomy fusion. J Neurosci Nurs 37:97-100, 2005

6. Garringer SM, Sasso RC: Safety of anterior cervical discectomy and fusion performed as outpatient surgery. J Spinal Disord Tech 23:439-443, 2010

7. Lied B, Rønning PA, Halvorsen CM, Ekseth K, Helseth E: Outpatient anterior cervical discectomy and fusion for cervical disk disease: a prospective consecutive series of 96 patients. Acta Neurol Scand 127:31-37, 2013

8. Liu JT, Briner RP, Friedman JA: Comparison of inpatient vs. outpatient anterior cervical discectomy and fusion: a retrospective case series. BMC Surg 9:3, 2009

9. Marawar S, Girardi FP, Sama AA, Ma Y, Gaber-Baylis LK, Besculides MC, et al: National trends in anterior cervical fusion procedures. Spine (Phila Pa 1976) 35:1454-1459, 2010

10. Patil PG, Turner DA, Pietrobon R: National trends in surgical procedures for degenerative cervical spine disease: 19902000. Neurosurgery 57:753-758, 2005

11. Pugely AJ, Martin CT, Gao Y, Mendoza-Lattes SA: Outpatient surgery reduces short-term complications in lumbar discectomy: an analysis of 4310 patients from the ACS-NSQIP database. Spine (Phila Pa 1976) 38:264-271, 2013

12. Sheperd CS, Young WF: Instrumented outpatient anterior cervical discectomy and fusion: is it safe? Int Surg 97:8689, 2012

13. Silvers HR, Lewis PJ, Suddaby LS, Asch HL, Clabeaux DE, Blumenson LE: Day surgery for cervical microdiscectomy: is it safe and effective? J Spinal Disord 9:287-293, 1996

14. Singhal A, Bernstein M: Outpatient lumbar microdiscectomy: a prospective study in 122 patients. Can J Neurol Sci 29:249-252, 2002

15. Smith GW, Robinson RA: The treatment of certain cervicalspine disorders by anterior removal of the intervertebral disc and interbody fusion. J Bone Joint Surg Am 40-A:607-624, 1958

16. Tomaras CR, Blacklock JB, Parker WD, Harper RL: Outpatient surgical treatment of cervical radiculopathy. J Neurosurg 87:41-43, 1997

17. Villavicencio AT, Pushchak E, Burneikiene S, Thramann JJ: The safety of instrumented outpatient anterior cervical discectomy and fusion. Spine J 7:148-153, 2007

18. Wang MC, Kreuter W, Wolfla CE, Maiman DJ, Deyo RA: Trends and variations in cervical spine surgery in the United States: Medicare beneficiaries, 1992 to 2005. Spine (Phila Pa 1976) 34:955-963, 2009

19. Zahrawi F: Microlumbar discectomy. Is it safe as an outpatient procedure? Spine (Phila Pa 1976) 19:1070-1074, 1994

\section{Disclosures}

Dr. Asher reports being the director of the National Neurosurgery Quality and Outcomes Database.

\section{Author Contributions}

Conception and design: McGirt, Devin. Acquisition of data: McGirt, Godil. Analysis and interpretation of data: McGirt, Godil, Parker, Devin. Drafting the article: McGirt, Godil. Critically revising the article: Asher, Parker, Devin. Reviewed submitted version of manuscript: Asher, Parker, Devin.

\section{Correspondence}

Matthew J. McGirt, Department of Neurosurgery, Carolina Neurosurgery \& Spine Associates, 225 Baldwin Ave., Charlotte, NC 28204. email: matt.mcgirt@cnsa.com. 